\title{
Achieving drinking water compliance levels for metaldehyde with an acclimated sand bioreactor
}

Catherine A. Rolph ${ }^{a}$, Bruce Jefferson ${ }^{a}$, Adam Brookes ${ }^{b}$, Francis Hassard and Raffaella Villa $^{c}$

${ }^{a}$ Cranfield University, Bedfordshire, MK43 OAL, UK.

${ }^{b}$ Anglian Water, Thorpewood house, Peterborough

c De Montfort University, Leicester, LE1 9HB, UK.

\begin{abstract}
Metaldehyde removal was delivered to below the $0.1 \mu \mathrm{g} \mathrm{L} \mathrm{L}^{-1}$ regulatory concentration in a laboratory scale continuous upflow fluidised sand bioreactor that had undergone acclimation through selective enrichment for metaldehyde degradation. This is the first reported case of successful continuous flow biological treatment of metaldehyde from real drinking water sources treating environmentally realistic metaldehyde concentrations. The impact of the acclimation process was impermanent, with the duration of effective treatment directly related to the elevated concentration of metaldehyde used during the enrichment process. The efficacy of the approach was demonstrated in continuous flow columns at both laboratory and pilot scale enabling degradation rates of between 0.1 and $0.2 \mathrm{mg} \mathrm{L}^{-1} \mathrm{~h}^{-1}$. Future work needs to focus on optimisation of the sand bioreactor and the acclimation process to ensure viability and feasibility of the approach at full scale.
\end{abstract}




\section{Introduction}

The use of pesticides to support modern intensive crop production leads to an unavoidable movement of a proportion of the applied chemicals from the agricultural environment into connected receiving waters. Where the water is subsequently used for abstraction for potable water production elevated levels of specific pesticides can periodically enter the treatment works leading to the risk of exceeding the maximum allowable concentration (MAC) of $0.1 \mu \mathrm{g}$ $\mathrm{L}^{-1}$ for any individual pesticide and $0.5 \mu \mathrm{g} \mathrm{L}^{-1}$ in total (The Council of the European Union, 1998). Traditional treatment trains incorporating ozone and GAC are effective at managing a large number of these pesticides. However, pesticides such as metaldehyde, clopyralid, propyzamide and carbetamide are less well managed by such technologies leading to a number of non-compliant events (Cosgrove et al, 2019). Currently, metaldehyde is the pesticide of greatest concern in the UK accounting for 1131 of the 1571 pesticide compliance failures reported between 2000 and 2016 (Cosgrove et al., 2019). Elevated levels are most commonly observed from late summer to winter, especially when a period of heavy rainfall follows a prolonged dry period (Cosgrove et al., 2019, Rolph et al., 2019). Reported concentrations are typically up to $10 \mu \mathrm{g} \mathrm{L}^{-1}$ in the field and up to $1-2 \mu \mathrm{g} \mathrm{\textrm {L } ^ { - 1 }}$ at the treatment works and last for between 2 weeks and 2 months (Ramos et al. 2019; Cosgrove et al., 2019).

Metaldehyde is effectively taken up onto activated carbon but breakthrough occurs very quickly with reported regeneration frequencies of around 44 days (Hall, 2010). This can be managed by switching to PAC (Sanchez, 2017) or switching to an advanced oxidation processes such as $\mathrm{UV} / \mathrm{H}_{2} \mathrm{O}_{2}$ (Autin et al., 2012); examples of both exist at full scale. However, neither are particularly desired due to operational and cost challenges associated with their implementation. Accordingly, there is a need to see alternative options evolve that can provide resilient treatment in a more sustainable way. 
Sites incorporating slow sand filters (SSF) have seen periods of elevated metaldehyde removal across the SSF suggesting a potential biological pathway (UKWIR, 2011). Metaldehyde is known to be degraded aerobically in soils with a heat of combustion of $3370 \mathrm{KJ} \mathrm{mol}^{-1}$ when converted to $\mathrm{CO}_{2}$ such that it has the potential to be a carbon source for microbial growth (Eckert et al., 2006). Further, the transformation product is acetaldehyde, a precursor of acetylcoA which is central to many degradation pathways yielding twice the energy than glucose (Bieri, 2013). Indeed, effective biological removal of metaldehyde has been reported in water and aquatic sediments (Coloso et al., 1998; Calumpang et al., 1995). Recently, metaldehyde degrading microbes have been isolated from domestic soils (Thomas et al., 2017). The cultured isolates, identified within the genera Acinetobacter and Variovorax, were able to degrade metaldehyde as a sole carbon and energy source in elevated concentrations of $500 \mathrm{mg} \mathrm{L}^{-1}$. The two cultures were seen to have different rates of growth and utilisation rates of the substrate. Further, Acinetobacter was unable to grow with alternative carbon sources such as glucose, fructose, arabinose or glycerol but could grow on acetate (Thomas et al., 2017). Growth with metaldehyde was shown to increase the rate of metaldehyde degradation by a factor of 2 over the culture grown in acetate such that the culture was able to degrade a $50 \mu \mathrm{M}\left(8.8 \mathrm{mg} \mathrm{L}^{-1}\right)$ solution to below the detection limit $<1 \mathrm{nM}$ within 30 minutes. Translation to environmental waters that are encountered in drinking water treatment differ in that the metaldehyde exists as a micropollutant (1-2 $\left.\mu \mathrm{g} \mathrm{L}^{-1}\right)$ within a background water with a dissolved organic concentration of several $\mathrm{mg} \mathrm{L}^{-1}$ representing a mole ratio of around 1:10,000 (Rolph et al., 2018). In such cases, established belief is that removal occurs via secondary substrate utilisation or cometabolism (Zearley and Summers, 2012). However, recent findings suggest that metaldehyde may be a suitable primary carbon source even at low concertation (Thomas et al., 2017) offering the potential for selective enrichment of metaldehyde degrading organisms which then remove metaldehyde in periods of elevated concentration (Costerton et al., 1995; Wingender 
and Jaeger, 2002). Support for this has been provided in batch tests treating spiked real waters where the degradation rates over a 72 hour period increased in line with spike concentration (Rolph et al., 2019).

Translation to continuous flow systems has not been reported to date although illustration exist for other pollutants suggesting that metaldehyde may be able to be biologically treated as part of a drinking water flowsheet. For instance, fluidised bed bioreactors (FBBR) have been successfully utilised for removal of perchlorate, phenol, and NOM (Han et al., 2013; Vinod and Reddy, 2005; Webster et al., 2009). This includes pesticides such as mecoprop, glyphosate and bentazone where successful treatment was demonstrated in laboratory scale sand beds operated at hydraulic residence times of up to 60 minutes (Hedegard and Albrechtsen, 2013). Full scale trials related to the treatment of mecoprop revealed degradation rates between 0.09 and $0.96 \mathrm{mg} \min ^{-1}$ ton $_{\text {sand }^{-1}}$ with hydraulic residence times between 8 and 63 minutes (Hedegaard et al., 2014). The current paper posits that an appropriately operated fluidised sand bioreactor that is acclimated through selective enrichment will be effective in delivering metaldehyde compliant water when treating environmentally relevant concentrations. To test this, water collected from within an active drinking water works was treated in a continuously operated sand bioreactor containing sand from the site and was operated in upflow (fluidised) and downflow directions across a range of hydraulic residence times. The optimum arrangement was then used to trial a series of enrichment spikes to ascertain the impact on the resilience of treatment before scaling up the trial to a $100 \mathrm{~L}$ pilot sand bioreactor operated continuously for 100 days. 


\section{Materials and methods}

\section{Chemicals and natural water characteristics}

Metaldehyde (99\%) was purchased from Fisher scientific (Loughborough, UK). Metaldehyde $\mathrm{d}_{16}$ was purchased from Qmx Laboratories (Thaxted, UK) and used as an internal standard. HPLC grade acetone, dichloromethane and methanol were obtained from Rathburn Chemicals (Walkerburn, UK). Acetone was used to clean all equipment before use to prevent metaldehyde contamination. For the laboratory scale sand bioreactor studies, raw water was collected weekly from an operational site following an initial roughing filter treatment with GAC (Table 1). The samples were stored in sealed plastic containers at $2^{\circ} \mathrm{C}$ in the dark until used. For the pilot trial, the raw water was pumped directly from a reservoir. In all cases, spiking of raw water was undertaken using a stock solution of $10 \mathrm{mg} \mathrm{L}^{-1}$ metaldehyde dissolved in ultrapure water (PureLab Option s7/15, 18.2M $\Omega \mathrm{cm}$ and TOC $<3 \mathrm{ppb}$ ).

Table 1: Raw water characteristics for lab and pilot studies

\begin{tabular}{ccc}
\hline Raw water characteristics & Lab scale study & Pilot study \\
\hline DOC $\left(\mathrm{mg} \mathrm{L}^{-1}\right)$ & $4.6( \pm 1.04)$ & $6.7( \pm 0.62)$ \\
$\mathrm{pH}$ & $8.1( \pm 0.21)$ & $8.3( \pm 0.02)$ \\
Turbidity $(\mathrm{NTU})$ & $2.78( \pm 2.25)$ & $7.5( \pm 10.22)$ \\
Total nitrogen $\left(\mathrm{mg} \mathrm{L}^{-1}\right)$ & $2.6( \pm 1.3)$ & $3.3( \pm 1.27)$ \\
Total phosphorus $\left(\mathrm{mg} \mathrm{L}^{-1}\right)$ & $0.22( \pm 0.085)$ & $0.13( \pm 0.03)$ \\
Conductivity at $20^{\circ} \mathrm{C}\left(\mu \mathrm{sm}^{-1}\right)$ & $315.36( \pm 35.11)$ & $662.5( \pm 16.26)$ \\
Metaldehyde concentration $\left(\mu \mathrm{g} \mathrm{L}^{-1}\right)$ & $0.16( \pm 0.15)$ & $0.17( \pm 0.07)$ \\
\hline
\end{tabular}

\section{Media}

Sand with an active biofilm was collected from a slow sand filter at an operational site in the east of England (see SI A). The sand size was characterised by a $\mathrm{d}_{10}$ of $0.48 \mathrm{~mm}$ and a $\mathrm{d}_{90}$ of 
$0.94 \mathrm{~mm}$. Sand media was selected as it already had an active biofilm and at the time of collection had been exposed to metaldehyde levels up to $0.5 \mu \mathrm{g} \mathrm{L}^{-1}$. Results from the treatment works indicated that significant metaldehyde reduction was occurring through the sand bed. The sand was collected in sterilised containers and stored in non-airtight (without the lid) polythene plastic containers at $4^{\circ} \mathrm{C}$ in the dark until used. Clean sand that had been through an onsite mechanical cleaning system (high shear washing and agitation; CDEnviro, Ireland) was also collected. Gravel (diameter $=10 \mathrm{~mm}$ ) was purchased locally and used as a support media in the columns. The gravel was washed in deionised water before use to remove any impurities. All equipment was either autoclaved or rinsed with nitric acid and then rinsed with acetone to prevent metaldehyde contamination. Both glassware and plastic containers were previously tested in batch and no adsorption detected (Rolph et al, 2019).

\section{Laboratory scale sand bioreactors: Batch and flow through trials}

Covered perspex columns with a diameter of $2.5 \mathrm{~cm}$ and a height of $50 \mathrm{~cm}$ (Bio-Rad Laboratories, Hemel Hempstead UK) were filled with $5 \mathrm{~cm}$ of gravel and $30 \mathrm{~cm}$ of active sand $(200 \mathrm{~g})$. This resulted in a media volume of $1.5 \times 10^{-4} \mathrm{~m}^{3}$.

Batch recycle experiments were undertaken with active and clean sand in an upflow configuration and with active sand in a downflow configuration. One litre of raw water spiked with $50 \mu \mathrm{g} \mathrm{L}^{-1}$ metaldehyde was recycled for nine days. Fluidisation to a $20-30 \%$ bed expansion was achieved by operating the sand bioreactors at a flow rate of $10 \mathrm{~L} \mathrm{~h}^{-1}$ resulting in a single pass EBCT of 0.8 minutes with the flow recycled through the sand bioreactors throughout the duration of the trial.

For flow-through experiments, the sand bioreactor was fed with raw water from $10 \mathrm{~L}$ containers to a $300 \mathrm{~mL}$ recycle reservoir which was twice the volume of the bed (Figure 1). The sand bioreactor was run under various contact times from 30-828 minutes. The contact time between 
the water and the sand was calculated by multiplying the number of times the recycle reservoir was cycled through the sand bioreactor before it was replaced from the inlet reservoir by the EBCT of the fluidised sand bioreactor. Each condition was held for at least one week to allow the system to stabilise; flow rates were adjusted using peristaltic pumps and the recycle pump and flow-through pump were controlled independently.

Following this, spiking experiments were undertaken on sand collected from an operational site that had not been exposed to metaldehyde concentrations above $0.2 \mu \mathrm{g} \mathrm{L}^{-1}$ for several months. Sand bioreactors were exposed to different concentrations of metaldehyde at a contact time of 150 minutes. Spike concentrations from 0.5 to $50 \mu \mathrm{g} \mathrm{L}^{-1}$ were applied to the column for five days and then removed and replaced with a spike of $0.5 \mu \mathrm{g} \mathrm{L^{-1 }}$ to represent an environmentally relevant metaldehyde influent concentration in order to show the impact this had on achieving compliance. The spiking experiment were conducted in the sequence of 2,10

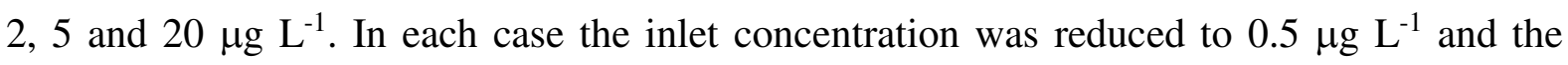
experiment continued until the effluent water become non compliant $\left(>0.1 \mu \mathrm{g} \mathrm{L}^{-1}\right)$. Higher spikes of 35 and $50 \mu \mathrm{g} \mathrm{L}^{-1}$ were conducted on fresh sand following the same procedure. Samples were taken regularly and analysed by GC-MS.

The raw water containers and all tubing (Tygon, Fisher scientific, UK) were sterilised frequently and the inlet water was changed at least weekly to prevent degradation of metaldehyde in the containers or tubing. All experiments were conducted in a temperature controlled laboratory set at $20-22{ }^{\circ} \mathrm{C}$ and the dissolved oxygen of the water periodically checked and was observed to remain above $1 \mathrm{mg} \mathrm{L}^{-1}$ throughout and hence conditions can be assumed to remain aerobic during the trials. 


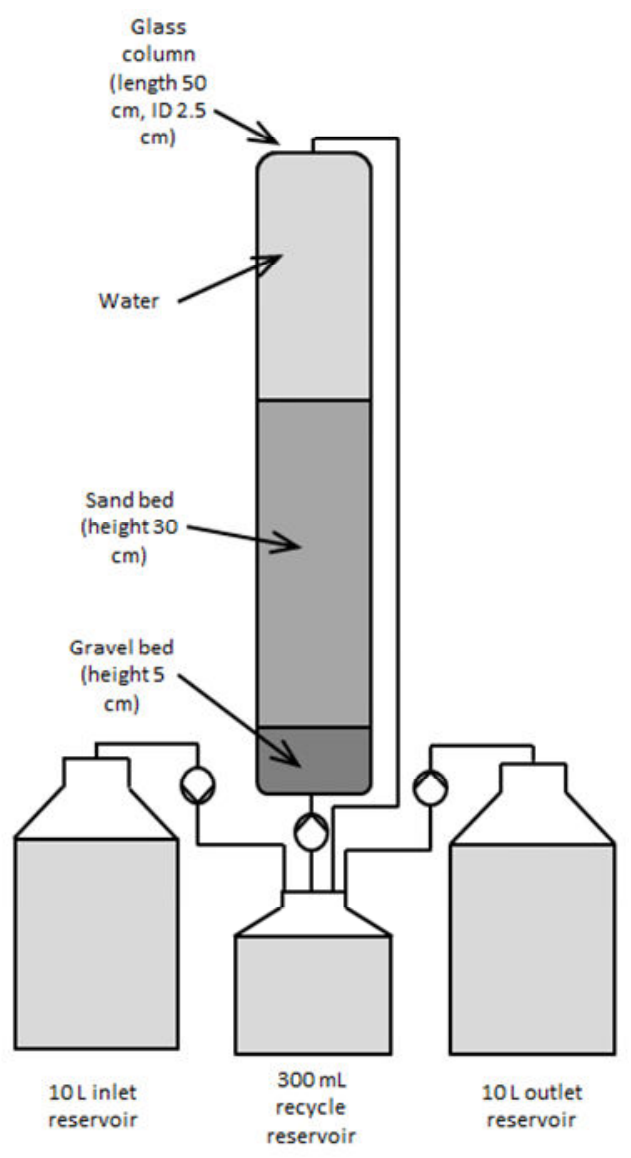

Figure 1: Lab scale sand bioreactor set up

\section{Pilot scale sand bioreactor}

A pilot scale sand bioreactor was installed at a treatment works in the Anglian Water region and supplied with untreated reservoir water. The rig was located in an unheated building to replicate operational conditions as closely as possible. Water was pumped directly from the reservoir to a holding tank before being fed to the sand bioreactor through PVC pipes. A $1.5 \mathrm{~m}$ Perspex column with a $0.2 \mathrm{~m}$ ID contained a $10 \mathrm{~cm}$ depth of gravel onto which a $50 \mathrm{~cm}$ depth of sand was added. The sand was a uniformly mixed combination of $50 \%$ biologically active sand filter (collected from an active filter) and 50\% clean sand with no biofilm to give a total media volume of $0.02 \mathrm{~m}^{3}$. The media was supported on a plinth with 5 nozzles for even distribution of the water through the column. The sand bioreactor was run for two weeks to allow biomass to develop throughout the bed. Recirculation was achieved with a positive 
displacement pump at a rate of $8-10 \mathrm{~L} \mathrm{~min}^{-1}$ equating to a fluidisation level of $5-10 \%$. A peristaltic pump provided the flow to the column at a rate of $0.27 \mathrm{~L} \mathrm{~min}^{-1}$ resulting in a media bed hydraulic retention time (HRT) of 67 minutes and a recycle ratio of 28.6. A $0.5 \mathrm{~m}$ x 0.41 m ID section of column was placed on top of the main column body to help prevent biomass washout. The total volume of the column was $0.1 \mathrm{~m}^{3}$. Degradation rates were calculated as the change in mass of metaldehyde divided by the contact time.

\section{Analytical Methods}

Determination of the metaldehyde concentration was performed using solid phase extraction (SPE) followed by analysis with gas chromatography-mass spectrometry (GC-MS). SPE cartridges (styrene-divinylbenzene cartridges Strata, $200 \mathrm{mg}$ per $3 \mathrm{~mL}$, Phenomenex, UK) were conditioned using $10 \mathrm{~mL}$ of methanol followed by $2 \mathrm{~mL}$ of ultrapure water. $2-250 \mathrm{~mL}$ of sample, spiked with metaldehyde $\mathrm{d}_{16}$ as an internal standard, was passed through the cartridge with a recovery that was greater than $94 \%$ throughout. The cartridge was rinsed with $2 \mathrm{~mL}$ of ultrapure water and dried under vacuum for 45 minutes. The samples were then eluted using 2 $\mathrm{mL}$ of dichloromethane before being evaporated to $0.5 \mathrm{~mL}$. Quantification was achieved using an Agilent 6890N gas chromatograph coupled with an Agilent 5673 mass selective detector with a limit of detection of $0.05 \mu \mathrm{g} \mathrm{L} \mathrm{L}^{-1}(\mathrm{GC}-\mathrm{MS}+\mathrm{SPE})$.

DOC was measured in non-purgable organic carbon (NPOC) mode using a Shimadzu 5000-A TOC analyser. All samples were filtered using a $0.45 \mu \mathrm{m}$ syringe filter (Millipore, Ireland) before analysis. 


\section{Results and Discussion}

\section{Impact of flow direction in batch sand bioreactor trials}

Flow direction had a significant impact on the lag time, rate of degradation and final concentration achieved during the batch column trials (Figure 2). For instance, minimal degradation occurred during the first 215 minutes when the sand bioreactor was operated in upflow compared to 645 minutes when operated in downflow. Thereafter, the rate of degradation observed in the upflow trials was more than twice that of the down flow direction at $0.045 \mu \mathrm{g} \mathrm{L}^{-1} \mathrm{~h}^{-1}$ compared to $0.092 \mu \mathrm{g} \mathrm{L}^{-1} \mathrm{~h}^{-1}$. Comparative beaker batch trials with nonacclimated sand reached a maximum degradation rate of $0.17 \mu \mathrm{g} \mathrm{L}^{-1} \mathrm{~h}^{-1}$, substantially higher than observed in the current trials (Rolph et al., 2019). Likewise, very high degradation rates of $668.8 \mu \mathrm{g} \mathrm{L}^{-1} \mathrm{~h}^{-1}$ have been reported during batch trials with isolated metaldehyde degraders exposed to high concentrations of metaldehyde (Thomas et al, 2017). The efficacy was further confirmed as the residual metaldehyde level reduced below the compliance target, reaching $0.049 \mu \mathrm{g} \mathrm{L}^{-1}$ after a total contact time of 860 minutes in the upflow sand bioreactor. In comparison, the downflow sand bioreactor never reached the $0.1 \mu \mathrm{g} \mathrm{L}^{-1}$ target, achieving a minimum of $0.36 \mu \mathrm{g} \mathrm{L} \mathrm{L}^{-1}$ after 1935 minutes. Similar findings have been reported for bulk DOC removal where the upflow configuration removed $10 \%$ more DOC than the downflow version (Han et al., 2013). The differences are attributed to better mass transfer and general mixing which aids maximum utilisation of the available reaction space.

A control upflow sand bioreactor with clean sand was observed to colonise quickly with $94 \%$ of the initial $50 \mu \mathrm{g} \mathrm{L}^{-1}$ metaldehyde spike attenuated after 9 days, equivalent to an actual contact time of the water with the media of 1935 minutes. However, a lag time of 5 days was observed before any removal occurred which aligns to the work of Rittmann and Brunner (1984) who reported small biofilm growth onto glass beads for four days followed by rapid increase in 
substrate removal from days $4-7$. Trials with isolated metaldehyde cultures also observed lag times of between 1-4 days depending on the species being used (Thomas et al., 2017). Ultimately these results confirm the ability to degrade metaldehyde to below compliance targets and supports the need to acclimate the microbial biomass through selective enrichment to ensure the sand bioreactor delivers a consistent treatment.

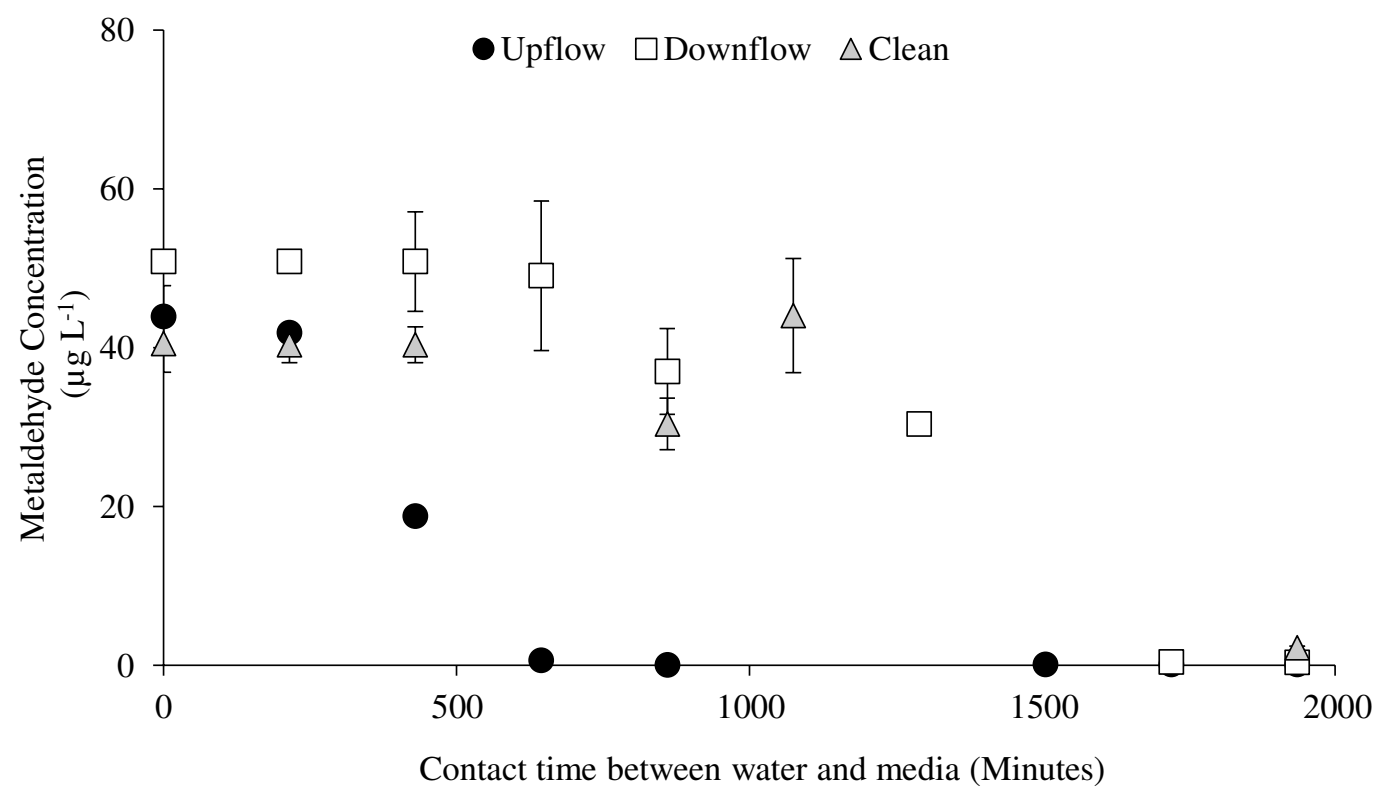

Figure 2: Metaldehyde removal in upflow and downflow sand bioreactors with active sand and $\square)$ and an upflow column with clean sand $(\triangle)$ operated in batch recycle mode. Initial metaldehyde concentration was $50 \mu \mathrm{g} \mathrm{L} \mathrm{L}^{-1}$

Effect of contact time on removal rate in a continuous flow-through sand bioreactor The sand bioreactors were then operated in flow-through, upflow mode with freshly collected sand (active) and operated at a contact time of 828 minutes. Different mean influent concentrations were observed for each trial with levels of 2.0, 2.0, 1.5. 1.8 and $1.3 \mu \mathrm{g} \mathrm{L}^{-1}$ for the trails with EBCTs of 30,100, 150, 300 and 828 minutes respectively. Steady removal of $52.7 \pm 4.2 \%$ was achieved under this configuration with effluent concentrations ranging from 
$0.20-0.26 \mu \mathrm{g} \mathrm{L} \mathrm{L}^{-1}$. This set up achieved good removal but not compliant water. The contact time was then decreased to between 30 and 300 minutes using a fresh sand sample for each EBCT to acovid cumulative impacts, whilst maintaining the same fluidisation rate. Variation in contact time demonstrated effective removal down to 150 minutes (Figure 3). To illustrate, residual metaldehyde concentrations of $0.5 \pm 0.2$ and $0.2 \pm 0.09 \mu \mathrm{g} \mathrm{L^{-1 }}$ were observed for contact times of 30 and 150 minutes respectively from influent concentrations of 2.0 and 1.5 $\mu \mathrm{g} \mathrm{L}^{-1}$ respectively. Extending contact time over 150 minutes gave no significant benefit for metaldehyde removal. This compares to one trial with the downflow configuration at a contact time of 176 minutes which resulted in no appreciable reduction $(\sim 2 \%)$ from an initial metaldehyde concentration of $1 \mu \mathrm{g} \mathrm{L}^{-1}$ (data not shown). However, no contact time was able to reduce the metaldehyde concentration below the target $0.1 \mathrm{mg} \mathrm{L}^{-1}$ level supporting the need for acclimation of metaldehyde degraders through selective enrichment.

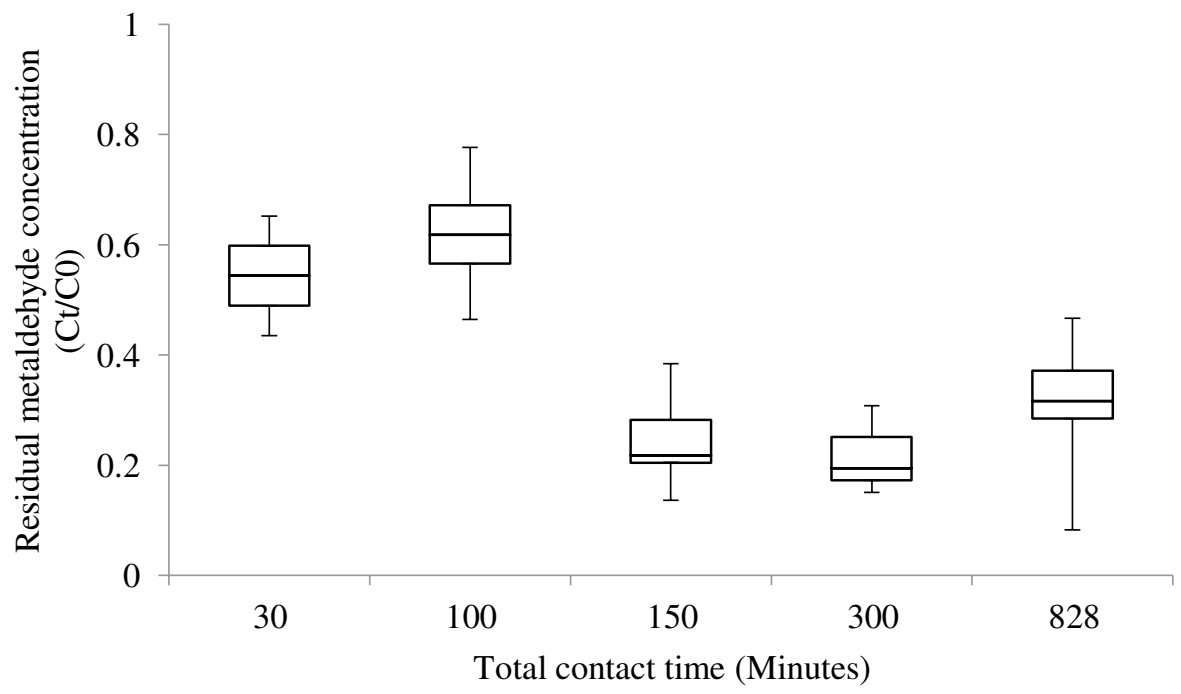

Figure 3: Impact of contact time on metaldehyde removal $(n=6)$ using active (nonacclimated) sand in sand bioreactors operated in flow-through, upflow mode. Inlet concentrations were 2.0, 2.0, 1.5, 1.8 and $1.3 \mathrm{mg} \mathrm{L}^{-1}$ for EBCTs of 30, 100, 150, 300 and 828 minutes 
The impact on microbial acclimation through selective enrichment was tested by using spikes of metaldehyde at different concentrations for 5 days for the upflow sand bioreactors operated with a 150 minutes contact time. Thereafter the influent was reduced to $0.5 \mu \mathrm{g} \mathrm{L}{ }^{-1}$ and the sand bioreactors operated for 10 days to establish the removal profile. Increasing the spike concentration resulted in an increased metaldehyde removal rate. This ranged from $67-86 \%$ with spikes ranging from $2-50 \mu \mathrm{g} \mathrm{L}^{-1}$; this is a larger removal than has been observed in previous experiments at a concentration of $0.5 \mu \mathrm{g} \mathrm{L}^{-1}$ (unspiked trials), even with an extended contact time of 828 minutes. The average metaldehyde removal rate following spiking showed a positive trend with increasing spike concentrations leading to an increase in the removal rate up to a maximum of $0.17 \mu \mathrm{g} \mathrm{L}^{-1} \mathrm{~h}^{-1}$ (Figure 4A). Larger spike concentrations also lead to an increased number of days that compliant water could be achieved once the sand bioreactor was switched to treating $0.5 \mu \mathrm{g} \mathrm{L}{ }^{-1}$ water (Figure 4B). All spike concentrations resulted in an increased efficacy. However, only spikes above $5-10 \mu \mathrm{g} \mathrm{L}^{-1}$ produced compliant water for any length of time.

The observed degradation rates achieved after acclimatisation are the same as those reported for batch kinetic trials with non-acclimatised sand and around half the rate observed with acclimated sand at $50 \mu \mathrm{g} \mathrm{L}{ }^{-1}$ (Rolph et al., 2019). However, the rates are significantly lower than those reported with isolated culture trials treating high concentrations (Thomas et al., 2017). This aligns with reports that the degradation follows Michaelis-Menton kinetics with a half rate constant of around $25-26 \mu \mathrm{g} \mathrm{L}^{-1}$ in an environmental batch system (Rolph et al., 2019) and $8.8 \mathrm{mg} \mathrm{L}^{-1}$ in an isolated pure culture treating solutions where metaldehyde is the only available substrate (Thomas et al., 2017).

Overall, the results support the notion that effective delivery of metaldehyde treatment is possible using a biological process as long as the sand bioreactor is acclimatised through selective enrichment. This has been previously established for linuron, pesticide mixtures and 
4-nitrophenol (Horemans et al., 2014; Tiam et al., 2014; Wiggins and Alexander, 1988). For instance, a biofilm developed over two weeks with high concentrations of galactose (300 mg $\mathrm{L}^{-1}$ ) was able to continue to degrade the galactose below a minimum substrate concentration $\left(S_{\min }\right)$ of $0.3 \mathrm{mg} \mathrm{L}^{-1}$ for at least 190 days (Rittmann and Brunner, 1984). In the case of Rittmann and Brunner (1984), it is thought that adaptation to oligotrophic conditions and other nutrients in the water prevented rapid biofilm decay and enabled sustained substrate removal. However, acclimatisation with high concentrations may not always be effective as it can lead to a population poorly adapted to removing trace levels of the target compound (Gözdereliler et al., 2013). The acclimatisation period used was 5 days throughout the study and this appears to be a suitable time period to deliver effective treatment. This mirrors work with $p$-nitrophenol (PNP) where 5 days was reported to be sufficient to adapt the microbial population to be able to degrade the pollutant (Spain and Van Veld, 1983). Further work is required to optimise this process and reduce time periods if possible, especially where the population has been previously exposure to elevated concentrations. In such cases, it is likely that the degraders sit dormant until an elevated concentration is available at which point they become active again (Wingender and Jaeger, 2002). Support for this is provided by the full-scale slow sand filters, which quickly start to degrade metaldehyde once the concentration exceeds $0.2 \mu \mathrm{g} \mathrm{L}^{-1}$ (Rolph et al., 2019). This offers the possibility of rapid start-up which can be triggered by early warning of elevated metaldehyde entering the treatment works. 

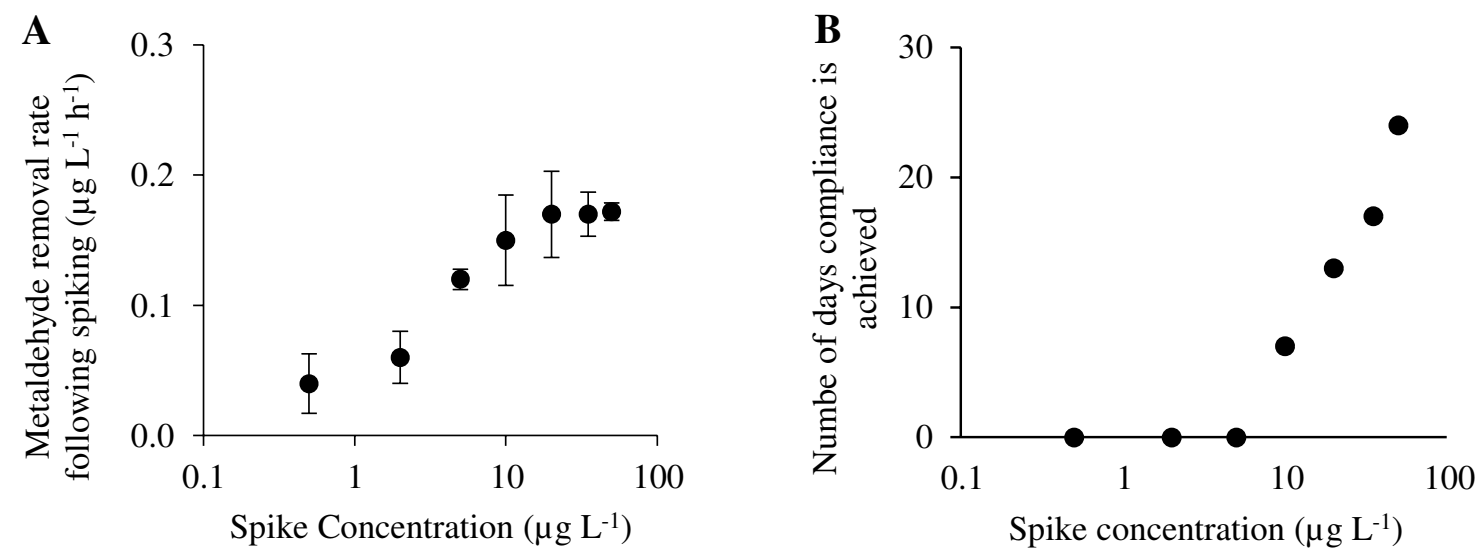

Figure 4 Acclimated sand in sand bioreactors operated in flow-through, upflow mode, with 150 minutes contact time. (A) Efficacy of the spike measured using an average removal rate for the 10 days following metaldehyde spiking; and (B) Number of days compliant water was produced.

\section{Validation at pilot scale}

To confirm the efficacy of metaldehyde degradation through acclimation, a parallel trial of the previous laboratory sand bioreactor was undertaken with a pilot sand bioreactor, treating the same water although the laboratory sand bioreactor received regular batches rather than a continuous input. The pilot sand bioreactor initially treated a spiked water at a concentration of $1 \mu \mathrm{g} \mathrm{L} \mathrm{L}^{-1}$ for 20 days. This was limited by site operational constraints and was selected to reflect levels that had previously seen enhanced degredation rates in the full scale system (Rolph et al, 2019). Thereafter, the column treated the incoming water to the site, which ranged from $0.1-0.9 \mu \mathrm{g} \mathrm{L}^{-1}$, compared to the $0.2-1.1 \mu \mathrm{g} \mathrm{L}{ }^{-1}$ received by the laboratory sand bioreactors. Degradation rates during this phase varied between 0.006 and $0.229 \mu \mathrm{g} \mathrm{L}^{-1} \mathrm{~h}^{-1}$ in the pilot plant and between 0.044 and $0.205 \mu \mathrm{g} \mathrm{L}^{-1} \mathrm{~h}^{-1}$ in the laboratory sand bioreactors (Figure 5). Comparative data from the full scale site revealed an degradation rates that varied between of 0.001 and $0.004 \mu \mathrm{g} \mathrm{L}^{-1} \mathrm{~h}^{-1}$ for an influent concentration of $0.17 \pm 0.07 \mathrm{mg} \mathrm{L}^{-1}$ thereby confirming 
the impact of acclimation even with a low influent concentration. The variability in the degradation rates reflect the nature of individual rate calculations such that the distribution of values is more important that any specific individual rate. Accordingly, the pilot sand bioreactors validated the findings and confirmed the suitability of biological treatment of pesticides down to very low levels. Whilst the spike level was lower than previously used it indicates that it is a combination of concentration and duration that can lead to enhanced performance.

Overall, this exemplifies the opportunity to utilise existing assets that have been adapted through acclimating the native biomass, negating the need to consider additional assets. Further work is required to optimise the design and operation of the systems and establish the best approaches to delivering acclimatisation on full-scale plants. Importantly, the relative merits of in-situ or ex-situ acclimation needs to be understood. In the former the native population would be acclimated through selective enrichment during a period when the biofilter was off line. In contrast, the adapted community could be cultured externally and seeded into the bioreactor for rapid start up. The relative economic viability and performance resilience of the two options needs to considered and engineered in a practical solution and should be considered a key area for future research in this field. In particular, understanding the duration of the spike for in-situ acclimation is required to assess its suitability. It is posited that significantly reduced spike duration should be possible once community has been previously established. 
- Lab scale $\square$ Pilot scale

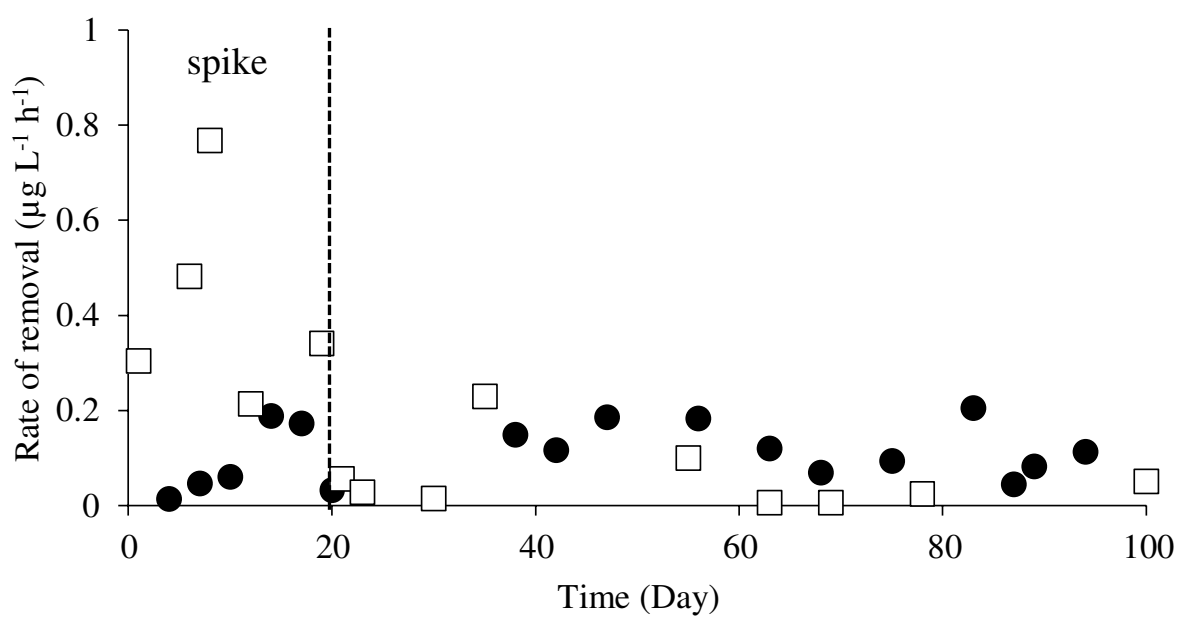

Figure 5: Rate of metaldehyde removal in pilot and labatory scale sand bioreactors, operated in flow-through, upflow mode, with 67 minutes contact time using acclimated sand (spiked with metaldehyde at $1 \mu \mathrm{g} \mathrm{L}{ }^{-1}$ for 20 days - marked with the dotted line). Inlet concentrations varied between $0.1-0.9 \mu \mathrm{g} \mathrm{L}^{-1}$ for the pilot scale and $0.2-1.1 \mu \mathrm{g} \mathrm{L}^{-1}$ for the laboratory scale

\section{Conclusions}

Biological treatment of pesticides in drinking water production has been shown to be an effective option in continuous flow sand bioreactors that have undergone acclimation through selective enrichment. In the current case, this was demonstrated for the pesticide metaldehyde in an upflow fluidised sand bioreactor where the compliance limit could be achieved for prolonged periods when the sand bioreactor was acclimated. In addition, without any acclimation, a FBBR was able to achieve more than $30 \%$ metaldehyde removal compared to the downflow process. The efficacy of the biotreatment was impermanent with its duration correlated to the level of enrichment undertaken. Importantly, in the case of metaldehyde an effective cycle of 30 days has been demonstrated which would be sufficient to manage the majority of elevated concentrations seen in the waters entering the drinking water treatment works. Future work is required to optimise the technology and the acclimation process to 
maximise operability for use in full scale treatment works and to establish if once initially enrichment is achieved, the re-activation periods can be reached in reduced time periods and at lower spike concentrations.

\section{Acknowledgements}

The authors gratefully acknowledge financial support from the Engineering and Physical Sciences Research Council (ESPRC) through their funding of the STREAM Industrial Doctorate Centre (EP/G037094/1) and from the project sponsors Anglian Water, Yorkshire Water and WRc.

\section{References}

Autin, O., Hart, J., Jarvis, P., MacAdam, J., Parsons, S. a. and Jefferson, B. (2012). Comparison of $\mathrm{UV} / \mathrm{H} 2 \mathrm{O} 2$ and $\mathrm{UV} / \mathrm{TiO} 2$ for the degradation of metaldehyde: Kinetics and the impact of background organics. Water Research. 46 (17). 5655-5662.

Bieri, M. (2003). The environmental profile of metaldehyde. In: World Agriculture, Bristich Crop Protection Council, Symposium Proceedings 80. 2003. Pp 255-260.

Calumpang, S.M.F., Medina, M.J.B., Tejeday, A.W. and Medina, J.R. (1995). Environmental Impact of Two Molluscicides: Niclosamide and Metaldehyde in a Rice Paddy Ecosystem. Bulleten of Environmental Contamination and Toxicology. 55. pp. 494501.

Coloso, R., Borlongan, I.G. and Blum, R.A. (1998). Use of metaldehyde as a molluscicide in semi-commercial and commercial milkfish ponds. Crop Protection. 17 (8). pp. 669674.

Cosgrove, S.L., Jefferson, B. and Jarvis, P. (2019) Pesticide removal from drinking water sources by adsorption. Environmental Technology Reviews, 8 (1). pp. 1-14.

Costerton, J.W., Lewandowski, Z., Caldwell, D.E., Korber, D.R. and Lappin-Scott, H.M. (1995). Microbial biofilms. Annual Reviews in Microbiology. 49, pp 711-745.

Council of the European Union (1998) Council Directive 98/83/EC of 3 November 1998 on the quality of water intended for human consumption. OJ L 330, 05.12.1998.

Eckert, M., Fleischmann, G., Jira, R., Bolt, H.M. and Golka, K. (2006) Acetaldehyde. In: Ullmann's Encyclopaedia of Industrial Chemistry. Wiley-VCH Verlag GmbH \& Co. KGaA.

Gözdereliler, E., Boon, N., Aamand, J., De Roy, K., Granitsiotis, M.S., Albrechtsen, H.-J. and Sørensen, S.R. (2013). Comparing metabolic functionalities, community structures, and dynamics of herbicide-degrading communities cultivated with different substrate concentrations. Applied and Environmental Microbiology. 79 (1). pp. 367-75.

Hall, T. (2010). Removal of metaldehyde and other pesticides. In: CIWEM drinking water quality conference on emerging contaminants and advanced treatment technologies. London, 23 March 2010. 
Han, L., Liu, W., Chen, M., Zhang, M., Liu, S., Sun, R. and Fei, X. (2013). Comparison of NOM removal and microbial properties in up-flow/down-flow BAC filter. Water Research. 47 (14). pp. 4861-8.

Hedegaard, M.J. and Albrechtsen, H.J. (2013). Microbial pesticide removal in rapid sand filters for drinking water treatment - Potential and kinetics. Water Research. 48 (1) pp. 7181 .

Hedegaard, M.J., Arvin, E., Corfitzen, C.B. and Albrechtsen, H.-J. (2014). Mecoprop (MCPP) removal in full-scale rapid sand filters at a groundwater-based waterworks. Science of the Total Environment. 499. pp. 257-64

Horemans, B., Hofkens, J., Smolders, E. and Springael, D. (2014). Biofilm formation of a bacterial consortium on linuron at micropollutant concentrations in continuous flow chambers and the impact of dissolved organic matter. FEMS Microbiology Ecology. 88. pp. 184-194.

Ramos, A., Whelan, M.J., Guymer, I., Villa, R and Jefferson, B. (2019) On the potential of online free-surface constructed wetlands for attenuating pesticide losses from agricultural land to surface waters. Environmental Chemistry. 16 (8). pp 563-576.

Rittmann, B.E. and Brunner, C.W. (1984). The nonsteady-state-biofilm process for advanced organics removal. Water Pollution Control Federation. 56. pp. 874-880.

Rolph, C.A., Jefferson, B., Hassard, F. and Villa, R. (2018) Metaldehyde removal from drinking water by adsorption onto filtration media: mechanisms and optimisation. Environmental Science: Water Research and Technology. 4 (10). pp1542-1552.

Rolph, C.A., Jefferson, B., Brookes, A., Choya, A., Iceton, G., Hassard, F. and Villa, R. (2019) From full scale biofiltration to bioreactors: engineering biological metaldehyde removal. Science of the Total Environment. 685. pp 410-418.

Sanchez Lopez, S. (2017) Metaldehyde Treatability by Dissolved Air Flotation Combined with Powdered Activated Carbon Adsorption. MSc Res Thesis. Cranfield University.

Spain, J.C. and Van Veld, P. a. (1983). Adaptation of natural microbial communities to degradation of xenobiotic compounds: Effects of concentration, exposure time, inoculum, and chemical structure. Applied and Environmental Microbiology. 45 (2). pp. 428-435.

Thomas, J.C., Moir, J.W.B., Helgason, T., Sinclaire, C. and Thwaites, R. (2013). The biotic degradation of Metaldehyde. Conference on Pesticide Behaviour in Soils, Water and Air. 2 September 2013, York.

Tiam, S.K., Morin, S., Pesce, S., Feurtet-Mazel, A., Moreira, A., Gonzalez, P. and Mazzella, N. (2014). Environmental effects of realistic pesticide mixtures on natural biofilm communities with different exposure histories. Science of the Total Environment. 473474. pp. 496-506.

UKWIR (2011). DW14: Treatment for new and emerging pesticides. London: UKWIR.

Vinod, A.V. and Reddy, G.V. (2005). Simulation of biodegradation process of phenolic wastewater at higher concentrations in a fluidized-bed bioreactor. Biochemical Engineering Journal. 24 (1). pp. 1-10.

Webster, T.S., Guarini, W.J. and Wong, H.S. (2009). Fluidized bed bioreactor treatment of perchlorate-laden groundwater to potable standards. Journal AWWA. 101 (5). pp. 137151. 
Wiggins, B.A. and Alexander, M. (1988). Role of Chemical Concentration and Second Carbon Sources in Acclimation of Microbial Communities for Biodegradation. Applied and Environmental Microbiology. 54 (11). pp. 2803-2807.

Wingender, J. and Jaeger, K-E. (2002). Extracellular enzymes in biofilms. In: G. Britton (ed) Encyclopaedia of Environmental Microbiology, 3. pp 1207-1222.

Zearley, T.L. and Summers, R.S. (2012). Removal of Trace Organic Micropollutants by Drinking Water Biological Filters. Environmental Science and Technology. 46. pp. 9412-9419. 